\title{
AN ECONOMICAL AND RELATIVELY EFFICIENT IMPLEMENTATION OF THE REAL-TIME SOLAR TRACKING SYSTEM
}

\author{
Sabir Ali Kalhoro \\ Department of Electronics Engineering NED University of \\ Engineering and Technology, Karachi (Pakistan) \\ E-mail: sabir13es66@gmail.com
}

Sayed Hyder Abbas Musvi

Indus University. Karachi (Pakistan)

E-mail: dean@indus.edu.pk

Sikandar Ali

Indus University. Karachi (Pakistan) E-mail: sikandar.shah@indus.edu.pk

Saadullah Rahoojo

Department of Geography, University of Sindh. Jamshoro (Pakistan)

E-mail:rahoojosaad@gmail.com

Asim Nawaz

Department of Geography University of Karachi. Karachi (Pakistan) E-mail: asimpmd@gmail.com

Recepción: 05/03/2019 Aceptación: 27/03/2019 Publicación: 17/05/2019

\section{Gitación sugerida:}

Kalhoro, S. A., Abbas Musvi, S. H., Ali, S., Rahoojo, S. y Nawaz, A. (2019). An economical and relatively efficient implementation of the Real-Time Solar Tracking System. 3C Tecnología. Glosas de innovación aplicadas a la pyme. Edición Especial, Mayo 2019, pp. 68-99. doi: http://dx.doi.org/10.17993/3ctecno.2019.specialissue2.68-99

Suggested citation:

Kalhoro, S. A., Abbas Musvi, S. H., Ali, S., Rahoojo, S. \& Nawaz, A. (2019). An economical and relatively efficient implementation of the Real-Time Solar Tracking System. 3C Tecnología. Glosas de innovación aplicadas a la pyme. Special Issue, May 2019, pp. 68-99. doi: http://dx.doi.org/10.17993/3ctecno.2019.specialissue2.68-99 


\section{ABSTRACT}

The bi-facial solar system which is available in the commercial markets having a variety of advantages and efficiency but they are too much costly. Therefore there is a dire need to design a low price solar system that overcomes the increasing energy demand. In this research, we have designed a system which reflects the bi-facial model with an economical prize for the developing nations. However, the efficiency of the proposed solar system was checked on a sunny day and its observation was closely related to the real-time bi-facial solar system. The prototype has been designed by combining the two equal watts solar penal having anti-parallel alignment with each other. The rear penal of the design system is supported by concentrator for strengthening the efficiency of the scattered irradiation. The scattered irradiation generates extra energy due to the design structure of the proposed system. The voltage of the system is conjoint increases slightly as the timely increasing irradiation strength. The power of the designed system increases with the increasing voltage proportional relationship with the current. The design system verifies the voltage, current and power measurement from all location of the calculation.

\section{KEYWORDS}

Renewable Energy, Solar System, Efficient Design System. 


\section{INTRODUCTION}

Nowadays deficiency of energy issues has been increasing which causes social and environmental problems, however, the developing countries urging the researchers to seek out alternative resources which may balance the demand for fossil fuel.

The alternative source like solar and wind are highly available to fulfill the increasing demand (Guerrero-Lemus, Vega, Kim, Kimm \& Shephard, 2016). While freely available solar irradiation is a reliable source of solar power generation and solar energy will be generated easily by harnessing the facility of the radiation, this energy source is clean and environmental friendly (Jia, Gawlik, Plentz \& Andrä, 2017; Luque, Torres \& Escobar, 2018). The energy from the sun intercepted by the earth is roughly $1.8 \times 1011 \mathrm{MW}$ which is several thousand times larger than the current consumption.

The most drawbacks with solar power are its dilute nature. Even within the hottest regions on the planet, the irradiation flux available nearly is inadequate for technological utilization. This drawback may be corrected by many techniques which ensure the greatest intensity of sun rays striking the surface of the panel from sunrise to sunset (Kim, Kim \& Hwang, 2018; Duan, Zhao, He \& Tang, 2018). This drawback can be overcome by the advanced design system, which is a bifacial solar system, it may generate electricity from either front or rear face, it will consider as the advanced photovoltaic system. This system is the noticeably exaggerated physical phenomenon of advance conversion system (Lamers, et al., 2018). We tend to gift here such type of model which associates in the alternating deposition technique such as bi-facial solar cells (Liu, Zhao, Duana, He, Zheng \& Tang, 2018). Such type of photovoltaic unit maximizes the output power by utilizing both sides of the PV cell to capture the maximum irradiation. The bifacial solar device yields and maximizes the efficiency of available system and this strategy provides new opportunities for fabricating high performance (Lo, Lim \& Rahman, 2015; Sun, Khan, Deline \& Alam, 2018). Bi-facial solar system which harvests the incident light irradiation from the front face and collects scattering 
light irradiation with the help of concentrator to facilitate the rear surface for the maximum utilization of light irradiation, therefore, system gain the best power outputs.

The rear face uses to increase the efficiency of the solar system as well as support the name bi-facial. The traditional aluminum metal is used to collect the scattered irradiation to get advantage from the useless irradiation and provide support to the rear pedal. The rear penal adds its power to increase the efficiency of the overall solar system. The scattered irradiation plays a significant rule for the rear side of the solar penal. The rear penal gets the advantage from the scattered irradiation to extract the maximum power from the bi-facial solar system (Pan, Cardoso, \& Reis, 2018). This system has a relatively little bit less photoelectrical conversion potency of the rear penal as compare to the front penal. The proposed system provides a significantly attainable application in the existing solar system. Generally, the designed system organized in well-observed alignments, thus partial sunlight is mirrored by the concentrator and throw toward the rear penal, so that requires energy might convert into thermal energy with the high efficiency by using the advanced bi-facial solar system (Zhu, Wang, Wang, Sun, He \& Tang, 2017).

The concentration of scattered irradiation in rear surface increases the overall efficiency of the designed system. All solar panels are in a much-maligned arrangement in a real application of electrical phenomenon power stations. The high-efficiency solar system expected to gain the scatter irradiation with the help of concentrator (Rodriguez, et al., 2018). The metallic portion encompasses a well-made reflection to the incident irradiation resulting in comparatively effective implementation of the system efficiency. A major motivation for the proposed system with a concentrator that is a program by the microcontroller known as Raspberry Pi for tracking the system to yield the additional energy. The mono facial panels are not so much reliable due to the light sensitivity as compare to the bifacial solar system. Most of the panel is using single access tracking system but we are motivated to design the bi-facial solar tracking system having two sides for the power extraction sides $\mathrm{X}$ at the front and $\mathrm{Y}$ for the 
rear penal to collect the scattered irradiation (Wang \& Lu, 2013; Patil \& Asokan, 2016). The potential of this improved module power output and energy yield was repeatedly commendable from all measurements through installations in numerous orientations. However, uncertainties regarding the particular output of this projected system still deter attainable investors. Even within the solar community, the important quantitative profit thanks to the bifacial system to suited technical ideas square measure still below discussion. The bi-facial solar system will dramatically improve the condition of generation compared to the existing solar system, so this type of advance model will gain a lot of attention in the future. This advanced solar model has been investigated intensively and characterized largely in the field with completely high gain. The proposed systems will provide the lump sum output power gain of the front and rear penal measurement. Such measurements were very reliable, so typically the different installation angles and backgrounds were terribly support to the effective measurement (Khalil, Asif, Anwar, Haq \& Illahi, 2017). Basically, the performance of this bidirectional solar system originates from the strength and angle of each location, and the scattered irradiation from the background at the rear penal. The precise nature of the bidirectional solar system would be more characterize at the well-defined research laboratory. Significantly the irradiation intensity level and the angle dependence area unit are highly important. The strength and angle dependences are individually investigated; no systematical collaborative investigations are performed on bidirectional solar system module.

In the old era mono-facial, solar cells were used without any tracking system. These systems were useful but with respect to time technology continuously changing by the research and technology by Scientist and demand by the consumers. They used mono-facial solar cells in combination with single access tracking system to increase the efficiency of the solar tracking system (Khan, et al., 2017). The rule of a bidirectional module is similar to it of a mono-facial one. In a mono-facial module, light radiation enters through the front side that absorbed by the solar PV and reborn into electrons that give electrical power. In this bidirectional module, an equivalent front side light irradiation assortment 
method happens and, additionally, light radiation is absorbed from the backside of the module (Rajshree, Jaiswal, Chaudhary \& Jayswal, 2016). This rear penal gets the solar irradiation source from the reflected collection of the irradiations by the concentrator from the ground or a neighboring row of PV modules. The extra light radiation generates a lot of electrons within the cells that primarily will increase the module efficiency. The voltage of the cell conjointly will increase slightly as the timely increasing irradiation strength so the power is increased because of the increasing voltage proportional relationship with the current. The most typical, bidirectional modules configuration is economical and viable reliable for the local as well as commercial usage. Bi-facial PV systems are highly compatible with already existing PV systems and generally achieve a markedly higher energy yield than mono-facial systems (Brady, Wang, Steenhoff \& Brolo, 2019). At the same time, bifacial systems are competitive because the manufacturing costs for the solar cells are slightly lower and the modern cell types are inherently bifacial and do not involve additional costs. Certified production technologies for the large--scale manufacture of bifacial cells and modules are already available on the market. The bifacial systems can be planned in exactly the same way as mono-facial systems, with a few factors demanding the extra attention, for example, the properties of the reflective ground. This attention will, however, be rewarded with a higher energy yield. Bifacial modules are opening up new application possibilities, often arising from the dual use of the installation area. All in all, bifacial modules can be employed to good advantage for most applications in terms of energy yield (Ooshaksaraei, Sopian, Zulkifli, Alghoul \& Zaidi, 2013). The single access tracking system is to work only one direction with the help of different microcontrollers. The proposed bifacial modules produce solar power from both sides front and rear side. Whereas the traditional panels are only designed to convert solar irradiance from one side of the module into dc power, the bifacial modules are manufactured with clear plates on both the front and back side of the solar cells. They are designed to convert solar irradiance from both sides into dc power (Solarworld, in google). Similar to mono-facial modules, bifacial modules come in a variety of types including framed and frameless. The reason for this growth in engagement with bifacial technology is 
the capacity to extract maximum power by utilizing the scattered irradiation. It has been calculated from the experiment that this model is able to increase the power output compared to the available solar configuration (Sengupta, 2016).

The bi-facial with the tracking system has been made an effort to track the motion of the sun for collecting maximum energy. The power generation with the help of a bi-facial solar tracking system is much more as compared to the single axis solar tracking system. In two several places, the require generation of the electricity is through the pricy fossil fuels. The user subjected to implies the restriction and pollutant environment that accompanies by fossil fuels (Renewables 2017 Global Status Report, 2017). The value intensive system should be placed in the way to protect the infrastructure and environment pollution. This implies the renewable energy to fulfill the growing demand. Today demand requires an easy plug and play electricity setup which provides an abundant solution in the way of power generation and consumption. This system involves in the autonomous frequent maintenance which will allow the alternative energy generation in an exceeding system which will be carried out in the form of the solar system (Livingston, Sivaram, Freeman \& Fiege, 2018).

\section{MODEL AND METHODS}

The bi-facial solar system model provides an effective measurement of power. The solar radiation such as global, diffuse and direct irradiation is fallen on the design solar system. These models are representing the principal climate phenomena to attain solar electricity. We analyze the output power of the proposed design system which is highly depending upon the Global Horizontal Irradiation (GHI) as well as Global Tilted Irradiation (GTI). The power of the system depends upon solar irradiation received by the surface of photovoltaic modules and the GHI is the sums of the direct and diffuse solar radiation $[\mathrm{kWh} / \mathrm{m} 2]$. The GHI is considered as a climate reference as it is an important parameter to check for the solar PV installation. 
The elevation angle measured relative to the sea level (ELE), also determines the optimum choice of a site and performance for the solar energy system. Elevation Angle can be measured by applying Eq. 1

$$
\operatorname{Cos} \theta=\sin \delta \sin \varphi+\operatorname{Cos} \delta \operatorname{Cos} \varphi \cos \omega
$$

Eq. 1

The zenith angle is the angle between the sun and the vertical. Thus making the zenith angle $=90^{\circ}-$ elevation as under Eq. 2 .

$$
\zeta=90-\theta
$$

Eq. 2

DNI (Direct Normal Irradiation): Solar radiation component that directly reaches the surface $\mathrm{kWh}$ per $\mathrm{m}$ square. It is significant for the proposed system as Eq. 3.

$$
\mathrm{DNI}=\mathrm{A} \cdot \exp (-\mathrm{B} / \operatorname{Cos} \theta)
$$

Eq. 3

DIF (Diffuse Horizontal Irradiation): Solar radiation component that is scattered by the atmosphere in $\mathrm{kWh} / \mathrm{m} 2 \mathrm{Eq} .4$.

\section{$\mathrm{DHI}=\mathrm{C} . \mathrm{DNI}$}

Eq. 4

GHI (Global Horizontal Irradiation): The GHI is the Sum of direct and diffuse solar radiation, $\mathrm{kWh} / \mathrm{m} 2$. It is considered as a climate reference as it is an important parameter to check for the solar PV installation which can be seen in Eq. 5.

$$
G H I=D H I+D N I \cdot \cos (\theta)
$$

Eq. 5

Atmospheric temperature, known as the air temperature is another most important variable determining the efficient performance of solar power systems.

The air temperature degrees or degrees determines the temperature of PV cells 
and modules and has a direct impact on PV energy conversion efficiency and resulting energy losses. Air temperature also some other weather parameters are the main part of each solar project assessment as they regulate the effective conditions and operation efficiency of the solar power plant (Please refer Eq. 6).

$$
\eta=\eta \operatorname{Tref}[1-\beta r e f(\operatorname{Tc}-\operatorname{Tref})]
$$

Eq. 6

The solar module is the most widely applied and also the most versatile technology for the power generation. The solar electricity simulation algorithm, incorporated in the atlas always provides an approximate estimate of the potential photovoltaic energy, which can be produced at any location covered by the interactive map, as shown in Eq. 7.

$$
\eta_{p v g}=\eta_{r} \eta_{p c}\left[1-\beta\left(T_{c}-T_{r e f}\right)\right]
$$

Eq. 7

Air temperature determines the temperature of PV cells and modules and has a direct impact on PV energy conversion efficiency and resulting energy losses. The operating conditions and operation efficiency of the solar power plant can be related to the air temperature model is given to find out the effecting temperature on the system as Eq. 8.

$$
T_{c}=T_{a}+\left(\frac{N O C T-20}{800}\right) G_{t}
$$

Eq. 8

The solar radiation model, air temperature model and PV power simulation model. These models provide location-specific solar radiation and temperature data. In order to calculate an on-demand utility by assessing the possible PV system type and configuration, the PV power simulation models are employed. The air temperature model and another PV power simulation model are given to find out the effecting temperature on the system as below Equations Eq. 9-11.

$$
\boldsymbol{P}_{p v}=\eta_{p v g} A_{p v g}
$$

Eq. 9 


$$
\begin{gathered}
\boldsymbol{P}_{\boldsymbol{M}}=\boldsymbol{I}_{\boldsymbol{S}} \boldsymbol{V}_{o c} . \\
\text { Eq. } 10 \\
\boldsymbol{P}_{\text {Array }}=\boldsymbol{N}_{\boldsymbol{s}} \boldsymbol{N}_{\boldsymbol{s}} \boldsymbol{P}_{\boldsymbol{M}}
\end{gathered}
$$

Eq. 11

The long-term yearly solar resource estimates by satellite--based models can be characterized by calculating the bias (systematic deviation) at the validation sites, where high-quality solar measurement are available. Also the World Bank choose the same as Eq.1-11 for solar potential calculation in the in the solar atlas so here these Eq.1-11 reflect the same model in this design system.

The polynomial function expresses the estimated best fit of the designed solar model at the available irradiation for the efficiency difference measurement of front and rear penal of the proposed solar system on any day of the month line by general polynomial function model, represented as Eq. 12 .

$$
y=a \cdot x^{\wedge} n+b \cdot x^{\wedge}(n-1)+c \cdot x^{\wedge}(n-2)+\ldots+m
$$

Eq. 12

$$
y=a \cdot x^{5}+b \cdot x^{4}+c \cdot x^{3}+d \cdot x^{2}+e \cdot x+m
$$

The voltage measurement of the proposed design solar system for the front and rear penal is fitted for the efficiency difference checking as shown in Figure 7. We have selected the dates from 08 to 10 of the Feb 2019 by using the polynomial regression of 6 degrees as, The quality of the best fit for the design system with the measured voltage data is determined by the value of $\mathrm{R} 2$ being close by 1 . In the case of voltage data the $\mathrm{R}^{2}=0.993$ for the front penal and $\mathrm{R}^{2}=0.9754$ for the rear panel. With the application, the polynomial of six degrees seems to be the best fit on the available data. The best fit in the case of front penal as shown in the Eq. 13.

$$
\begin{gathered}
y=-0.0002 \times 6+0.0102 \times 5-0.1795 \times 4+1.6129 \times 3-7.9224 \times 2+21.999 x-15.328 \\
\text { Eq. } 13
\end{gathered}
$$


And in the case of rear penal shown in the Eq. 14 .

$$
\begin{gathered}
y=0.0003 x 6-0.0135 \times 5+0.2317 x 4-1.9128 x 3+7.4858 x 2-9.0814 x+3.4818 \\
\text { Eq. } 14
\end{gathered}
$$

The measurement of current for front and rear solar penal is fitted for the efficiency difference checking of the designed solar system as shown in Figure 10. We have selected the dates from 08 to 10 of the Feb 2019 with the polynomial regression of 6 degrees as, The quality of the best fit with the irradiation data is determined by the value of $\mathrm{R} 2$ being close by 1 . In this case $\mathrm{R}^{2}=0.9595$ for the front penal and $\mathrm{R}^{2}=0.9509$ for the rear penal. With the application of the polynomial to 6 th degree seems to be the best fit on the available data. The best fit in the case of front penal as shown in the Eq.15.

$$
\begin{gathered}
y=6 E-05 x 6-0.0029 x 5+0.0508 x 4-0.4443 \times 3+1.9444 x 2-3.3536 x+1.8066 \\
\text { Eq. } 15
\end{gathered}
$$

And in the case of rear penal as shown in the Eq. 16.

$$
\begin{gathered}
y=7 E-05 x 6-0.003 \times 5+0.0513 x 4-0.4341 \times 3+1.849 x 2-3.1683 x+1.7129 \\
\text { Eq. } 16
\end{gathered}
$$

The power measurement of front and rear solar penal is fitted for the efficiency difference checking as shown in Figure 13. We have selected the dates from 08 to 10 of the Feb 2019 with the polynomial regression of 6th degree as, The quality of the best fit for the designed bi-facial solar system with the irradiation is determined by the value of $\mathrm{R} 2$ being close by 1 . In this case $\mathrm{R}^{2}=0.9677$ for the front penal and $\mathrm{R}^{2}=0.9676$ for the rear penal. With the application of the polynomial 6th degree seems to be the best fit on the available power measurement data. The best fit in the case of front penal as shown in the Eq. 17.

$$
\begin{gathered}
y=0.0007 x 6-0.0323 x 5+0.5627 x 4-5.0022 x 3+23.254 x 2-43.174 x+24.743 \\
\text { Eq. } 17
\end{gathered}
$$

And for the case of rear penal as shown in the Eq. 18. 


$$
\begin{gathered}
y=0.0007 \times 6-0.0276 \times 5+0.4603 \times 4-3.9598 \times 3+18.306 \times 2-34.732 x+20.41 \\
\text { Eq. } 18
\end{gathered}
$$

\section{SYSTEM DESIGN AND IMPLEMENTATION}

The proposed design solar system have Light dependent resistors (LDR) that use the light sensing element. We are using two 12 volts to a gear dc motor. The dc volt geared the motor so it is used for east-west tracking and other geared dc motor with a threaded rod for the linear up-down motion for north-south movement. The LDR's are sensing the light intensity as shown in Figure 2. The tracking of sun movement, in that way we can get optimum power of the solar system. The main object of the design system is to gain maximum power from the sun. The design system supports the tracking strategy as the annual motion of sun at 23.5o degree in east-west direction is occurred. In this project, the relay module is used for converting binary data to electrical output. The design system is controlled by the microcontroller known as raspberry pi. The raspberry pi is the main control unit of the design system. The raspberry pi microcontroller gets a signal from the sensor that decides the direction of the movement of the motors in the required axis. The python is used to program the raspberry pi for the tracking and control purpose. The Python is associated with the interpreter, interactive programming language. It incorporates modules, exceptions, dynamic writing, and terribly high level of dynamic knowledge.

\subsection{BLOCK DIAGRAM}

The basic blocks diagram consisting of Solar PV Panel, light dependent resistor (LDR), raspberry pi, relay module, analog to digital converter (ADG), power supply, and battery. The panel gets the irradiation and converts it into electricity or electrical signal. This generated electricity hold in the battery for upcoming use. The power will be flow from solar panels to store in the battery. The battery will be charged fully and get alarms for disconnection within the event of a fault. The microcontroller is placed in between the solar penal and battery for the tracking and the system control. The microcontroller has been used to generate 
the control commands from the LDR sensor. The microcontroller offers the motion to the motor to rotate the parabolic dish. The design system accuracy depends upon sensor and its accuracy is important for the successful performance of the algorithm. The last block is load, we are able to use any kind of dc load here as we have not inserted electrical converter block within the design system. The ac appliances on solar panels we need to feature electrical converter block in on top of the diagram in order that it can convert dc power provided by the solar battery into ac.

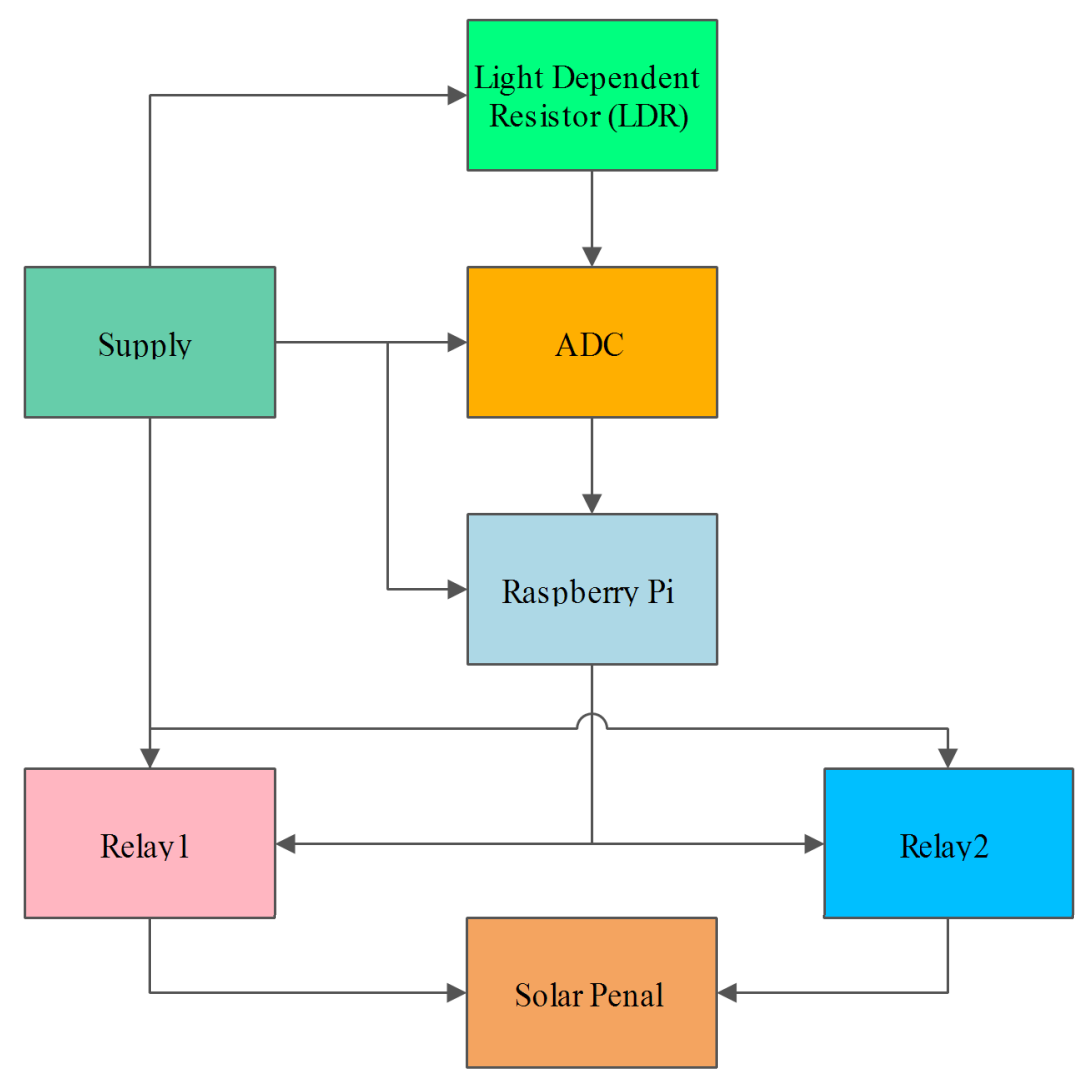

Figure 1. Flow Diagram of the Design Solar System.

\subsection{EXPERIMENTATION}

The potency of a mono-facial solar module is expected to decrease considerably as compared to the availability of the irradiation thanks to the bi-facial solar 
system to upgrade the efficiency of the solar system. The proposed design system consists of front and rear solar penal with a solar concentrator that gradually increase the efficiency of the reflected or scattered solar irradiation tipped on the rear side of the system. The solar modules square measure mounted beside one another on a metal frame. Each module is connected to a variable load depending on the requirement. The circuit includes a two-way relay switch that is tailored to the circuit to energize the motor to set the direction of the solar penal module at a time for measurement its output $\mathrm{I}-\mathrm{V}$ characteristics.

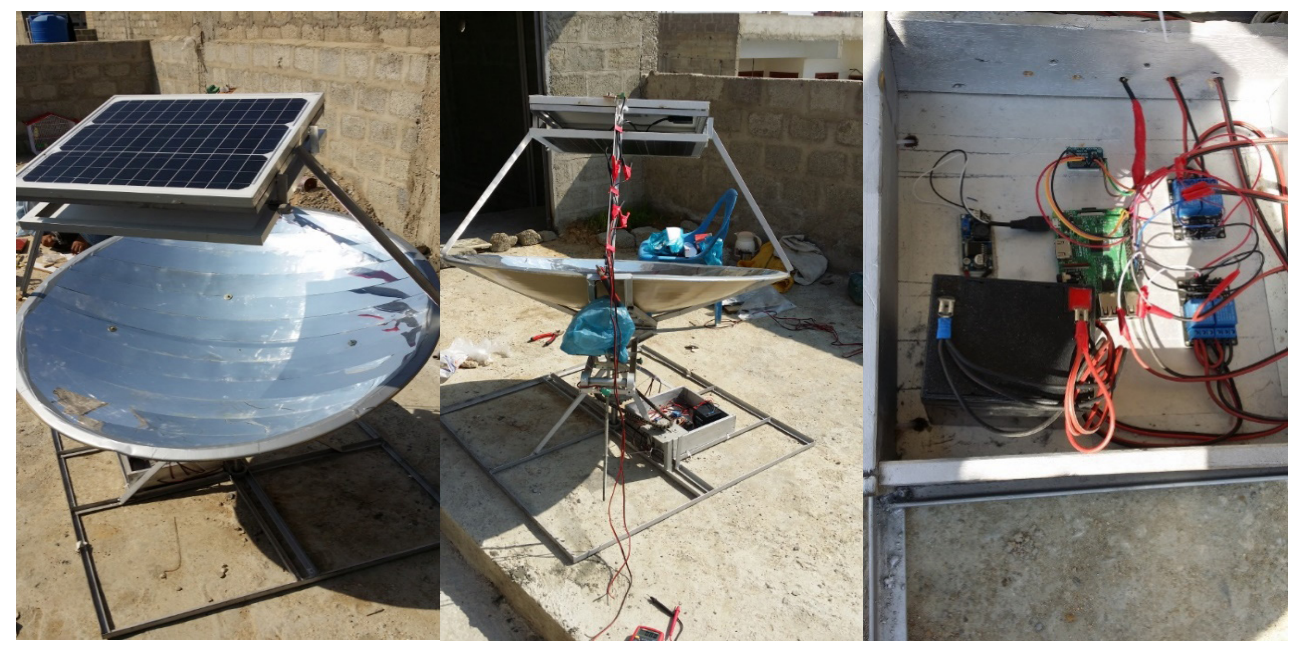

Figure 2. Experimental Setup of Design System.

\subsection{MEASUREMENT SETUP}

Digital Clamp Meter and Solar Power Meter are used for the measurement. The Digital Clamp Meter measures voltage, current, and power for each selected days and the solar power meter used to measure the solar irradiation. 

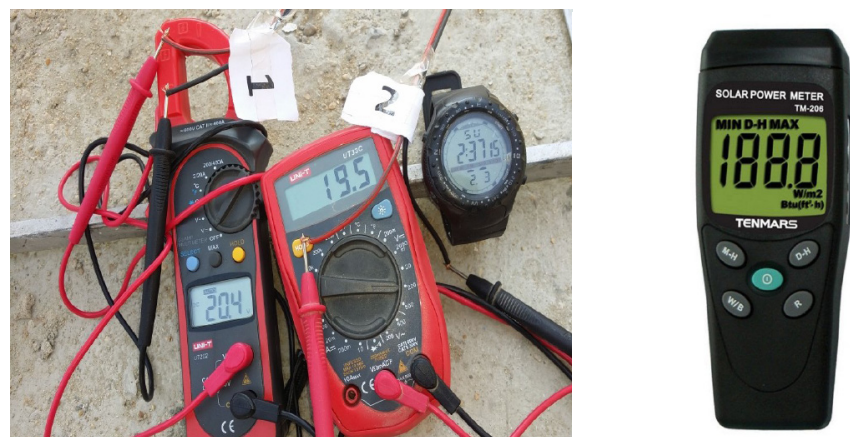

Figure 3. Digital Clamp Meter and Solar Power Meter.

\section{RESULTS AND DISCUSSION}

The specific period of result duration 08 to 10 of the Feb 2019, as of Friday, Saturday and Sunday are chosen for the resulting survey, we have to use the clamp meter for the voltage and the current measurement and solar power meter for the solar irradiation calculation as shown in the Figure 3. The measurement of the entire process proves that the proposed design system is feasible for the all advanced solar power system.

\section{SOLAR RADIATION MEASUREMENT}

The solar irradiation for each of the selected day is observed as shown in the Figures 4-5. Irradiation and air Temperature measurement analysis for the design solar PV system is shown in Figure 6. 

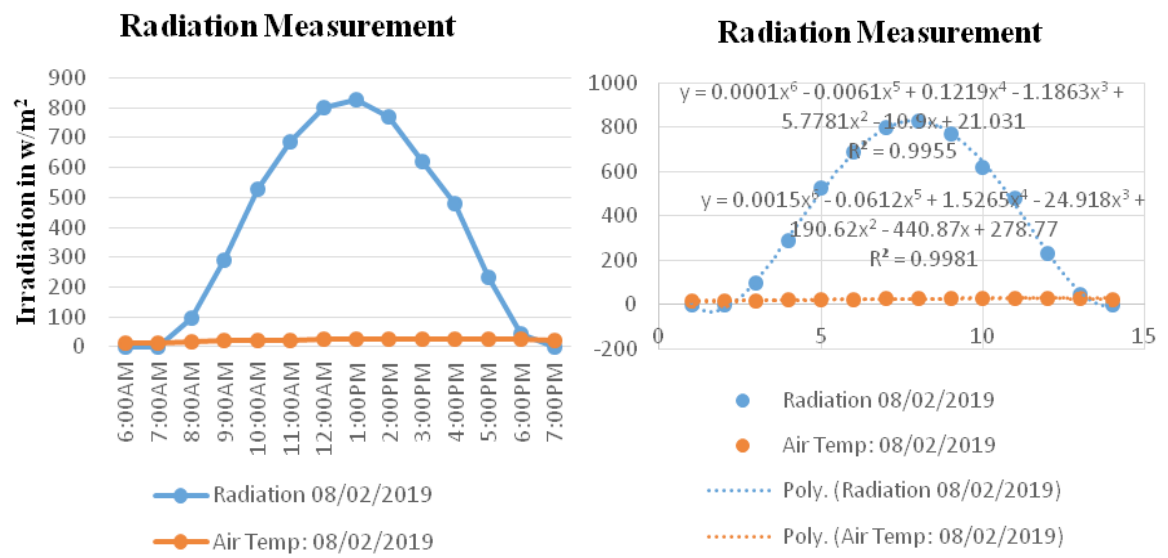

Figure 4. Irradiation and air Temperature measurement for the solar PV (Panel X1 and Y1) for the 1st-day experiment.

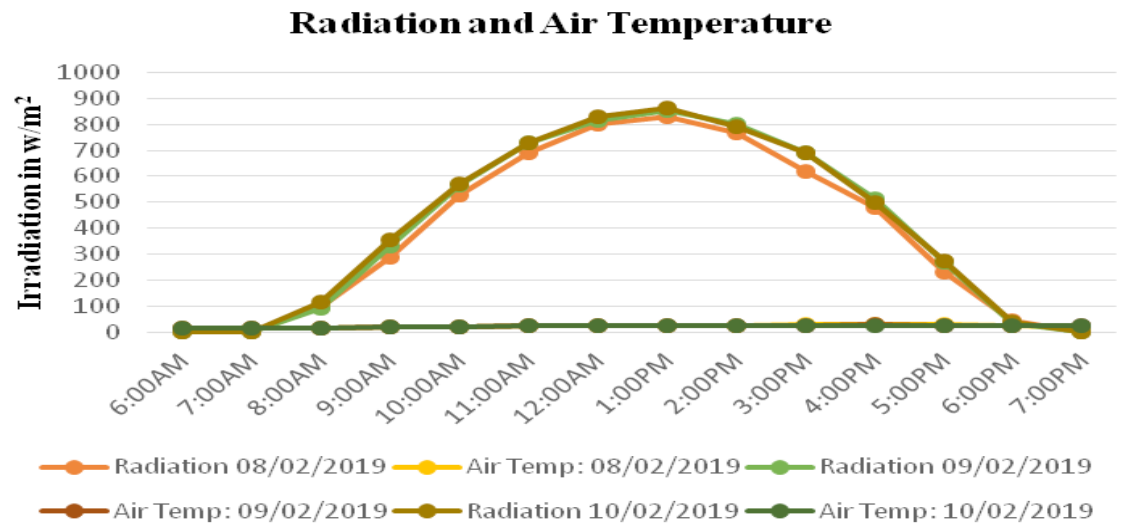

Figure 5. Irradiation and air Temperature measurement for the design solar PV system for 1st, 2nd, and 3rd-day experiment.

\section{Radiation and Air Temperature Analy sis}

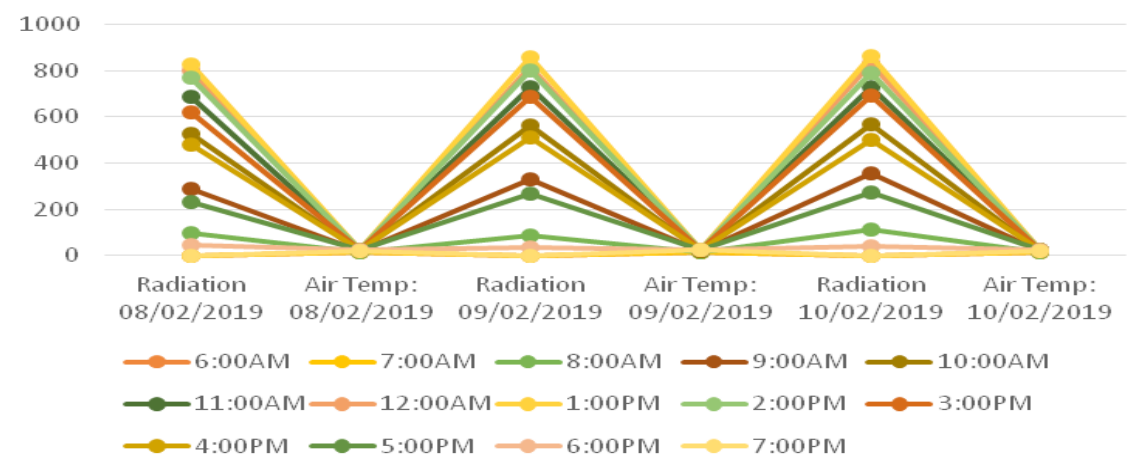

Figure 6. Irradiation and air Temperature measurement analysis for the design solar PV system for 1st, 2nd, and 3rd-day experiment. 


\section{VOLTAGE MEASUREMENT}

The voltage measurement of the design system is observed for the selected days Friday, Saturday and Sunday under the time frame of 6:00 AM to 7:00 PM. The $\mathrm{X}$ and $\mathrm{Y}$ show the front and rear side of the designed solar system. The $\mathrm{X} 1, \mathrm{X} 2$, and $\mathrm{X} 3$ show the selected 1st, 2nd and 3rd day of the front side measurement similarly Y1, Y2, and Y3 for the rear side measurement. It is observed that the voltage is maximum during 1:00 PM and a minimum at the 6:00 AM and 7:00 $\mathrm{PM}$ as shown in Figure 7. The voltage measurement of front and rear solar PV for the three days experiment is observed as shown in Figure 8. From the experiment, it is clearly observed that there is a little bit of output voltage discrimination between the front and rear solar penal. The voltage difference between the front and rear solar penal is due to the direct and scattered fall of solar irradiation. The direct fall of solar irradiation at the front penal and indirect or scattered irradiation fall on the rear solar penal make the difference in the observed voltage output as shown in Figure 9.
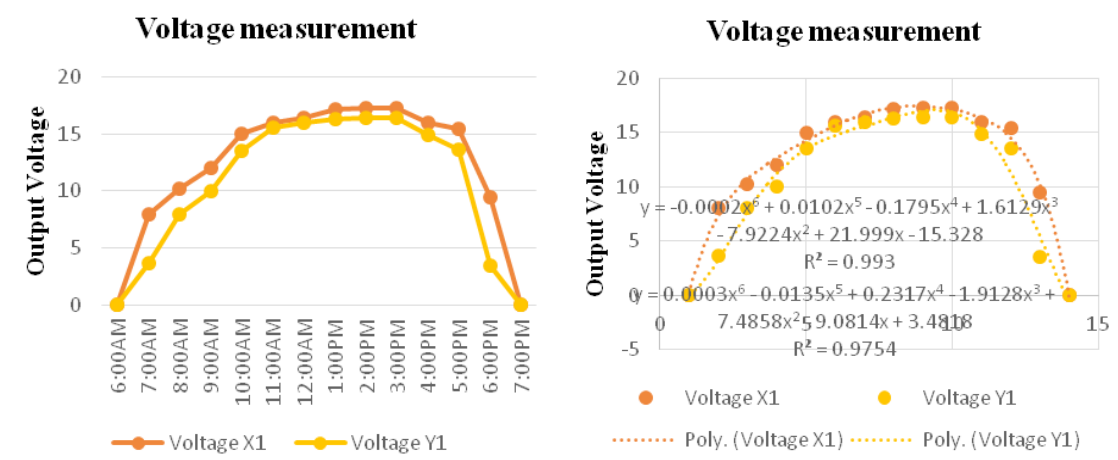

Figure 7. Voltage measurement of front and rear solar PV (Panel $\mathrm{X} 1$ and $\mathrm{Y} 1)$ for the 1st-day experiment. 
Three days Voltage measurement Experiment of Front and Rear Penal

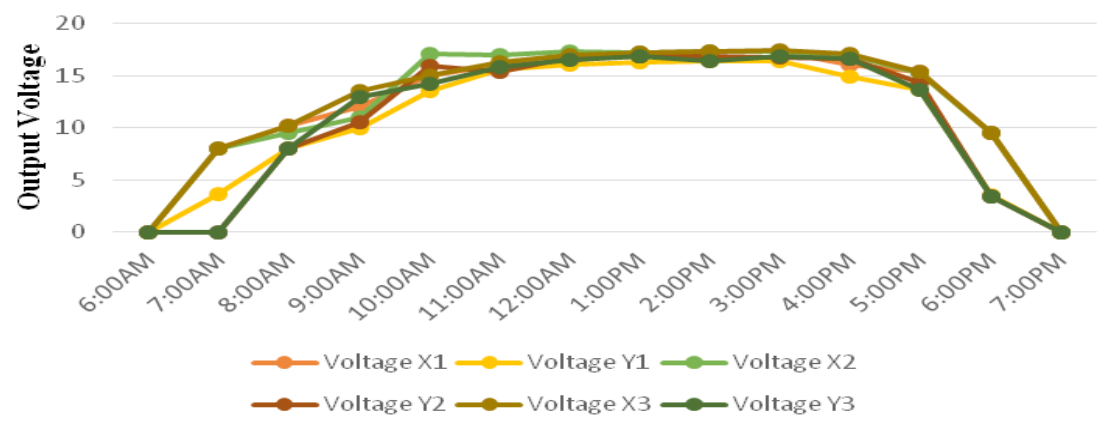

Figure 8. Voltage measurement of front and rear solar PV (Panel $X$ and $Y$ ) for 1st, 2nd, and 3rd-day experiment.

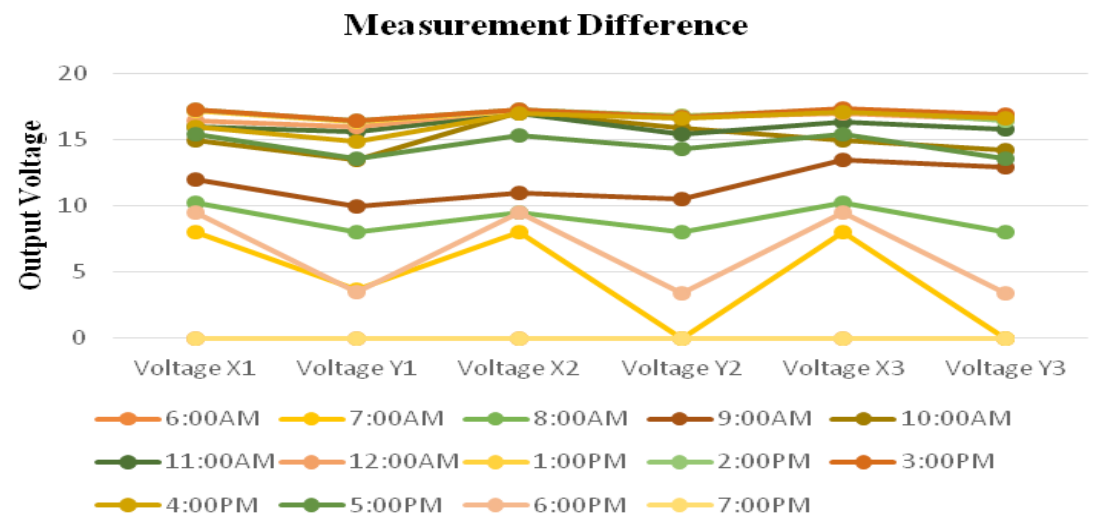

Figure 9. Voltage measurement difference between the front and rear solar PV (Panel $X$ and $Y$ ) for 1st, 2nd, and 3rd-day experiment.

\section{CURRENT MEASUREMENT}

The current measurement of the design system is observed for the selected days Friday, Saturday and Sunday under the time frame of 6:00 AM to 7:00 PM. The $\mathrm{X}$ and $\mathrm{Y}$ show the front and rear penal of the designed solar system. The X1, X2 and $\mathrm{X} 3$ show the selected 1st, 2nd and 3rd days of the front side measurement similarly Y1, Y2, and Y3 for the rear side measurement. It is observed that the current is maximum during 12:00 $\mathrm{AM}$ to 1:00 $\mathrm{PM}$ and a minimum at 6:00 $\mathrm{AM}$ and 7:00 PM as shown in Figure 10. The current measurement of front and rear solar PV (front panel X and rear penal Y) for the three days experiment 
is observed as shown in Figure 11. From the experiment, it is clearly observed that there is a little bit of output current discrimination between the front and rear solar penal. The current difference between the front and rear solar penal is due to the direct and scattered fall of solar irradiation. The direct fall of solar irradiation at the front penal and indirect or scattered irradiation fall on the rear solar penal make the difference in observed current output as shown in Figure 12.
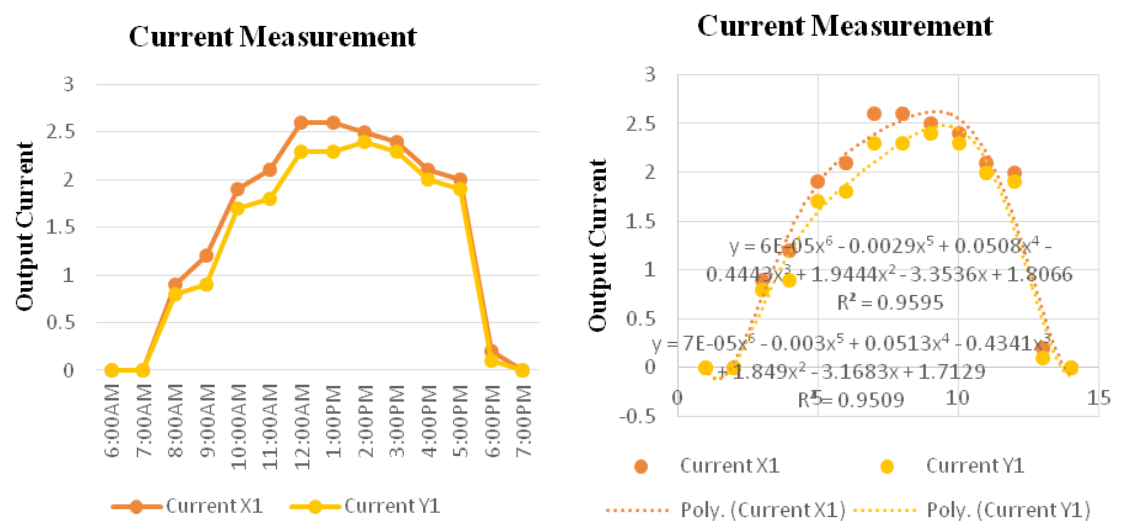

Figure 10. The current measurement of front and rear solar PV (Panel X1 and Y1) for the 1st-day experiment.

\section{Current Mea surement}

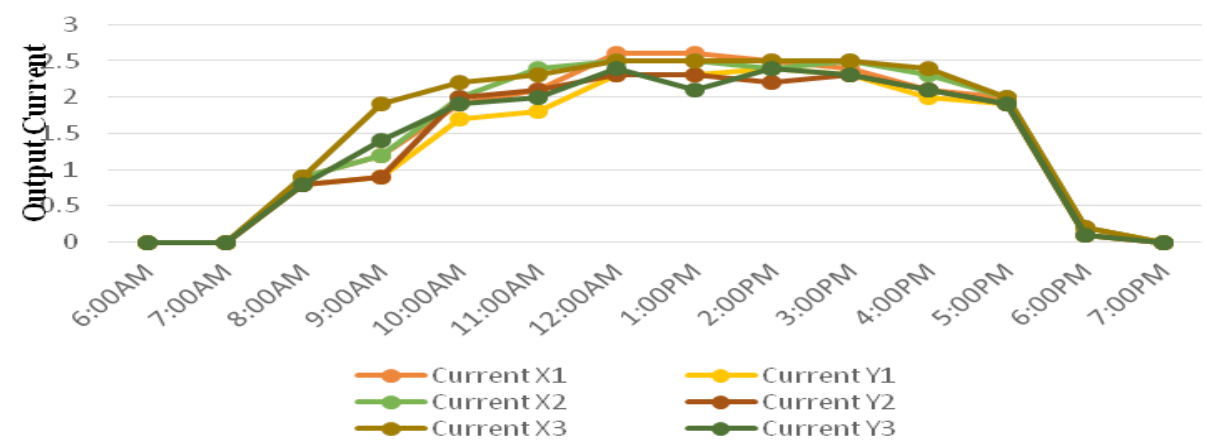

Figure 11. The current measurement of front and rear solar PV (Panel $X$ and $Y$ ) for 1st, 2nd, and 3rd-day experiment. 


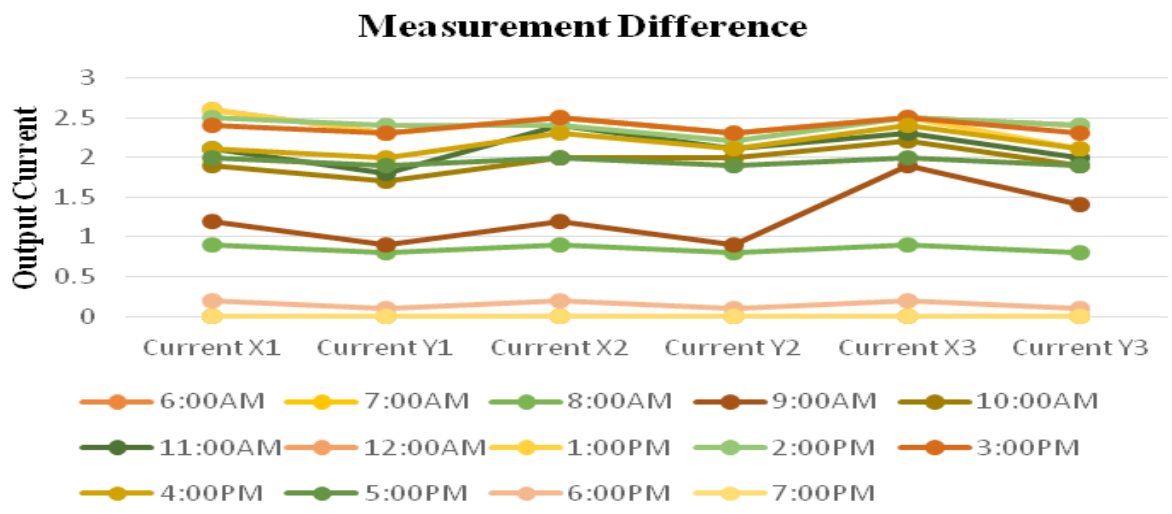

Figure 12. Current measurement difference between the front and rear solar $P V$ (Panel $X$ and $Y$ ) for 1 st, 2nd, and 3rd-day experiment.

\section{POWER MEASUREMENT}

The power measurement of the design system is observed for the selected days Friday, Saturday and Sunday under the time frame of 6:00 AM to 7:00 PM. The $\mathrm{X}$ and $\mathrm{Y}$ show the front and rear side of the designed solar system. The $\mathrm{X} 1, \mathrm{X} 2$ and $\mathrm{X} 3$ show the selected 1st, 2nd and 3rd days of the front side measurement similarly Y1, Y2, and Y3 for the rear side measurement. It is observed that the power is maximum during 1:00 PM and minimum at the 6:00 AM and 7:00 PM as shown in Figure 13. The Power measurement of front and rear solar PV (front panel $\mathrm{X}$ and rear penal $\mathrm{Y}$ ) for the three days experiment are observed as shown in Figure 14. From the experiment, it is clearly observed that there is a little bit of output power discrimination between the front and rear solar penal. The power difference between the front and rear solar penal is due to the direct and scattered fall of irradiation. The direct irradiation fall at the front penal and indirect or scattered irradiation fall on the rear penal make the difference in observed output power values as shown in Figure 15. 

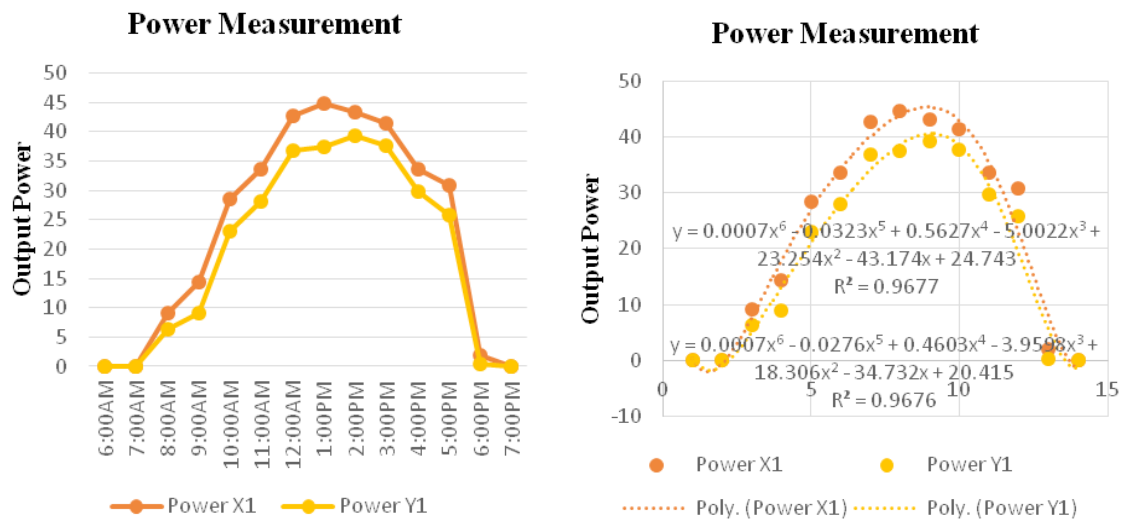

Figure 13. Power measurement of front and rear solar PV (Panel $\mathrm{X} 1$ and $\mathrm{Y} 1)$ for the 1st-day experiment.

\section{Power Measurement}

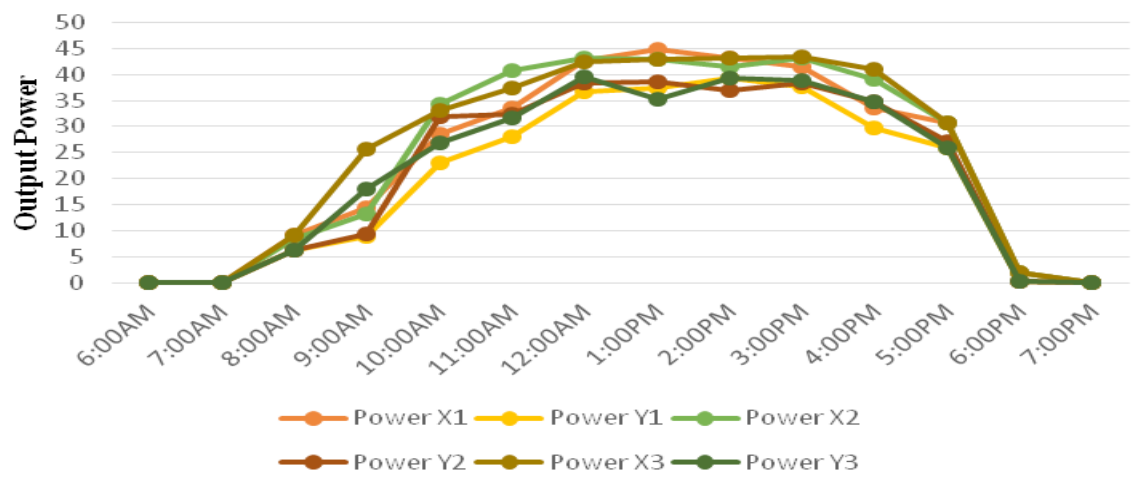

Figure 14. Power measurement of front and rear solar PV (Panel $X$ and $Y$ ) for 1st, 2nd, and 3rd-day experiment.

Measurement Difference

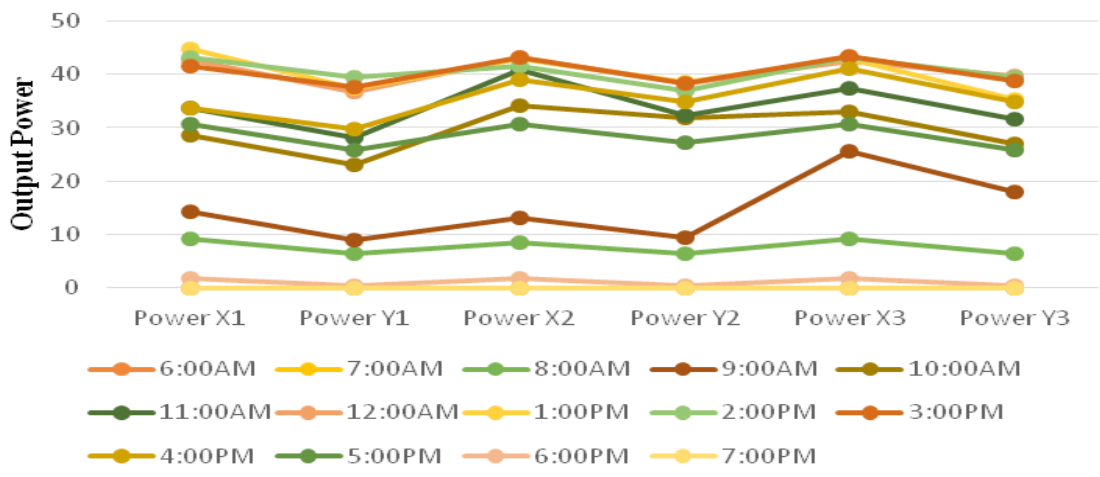

Figure 15. Power measurement difference between the front and rear solar $P V(P a n e l ~ X$ and $Y$ ) for 1st, 2nd, and 3rd-day experiment. 
The total three days voltage, current, and the power measurement is observed for the selected days as shown in Figure 16. The total values observation is based upon the addition of the front and rear penal voltage, current and power values.

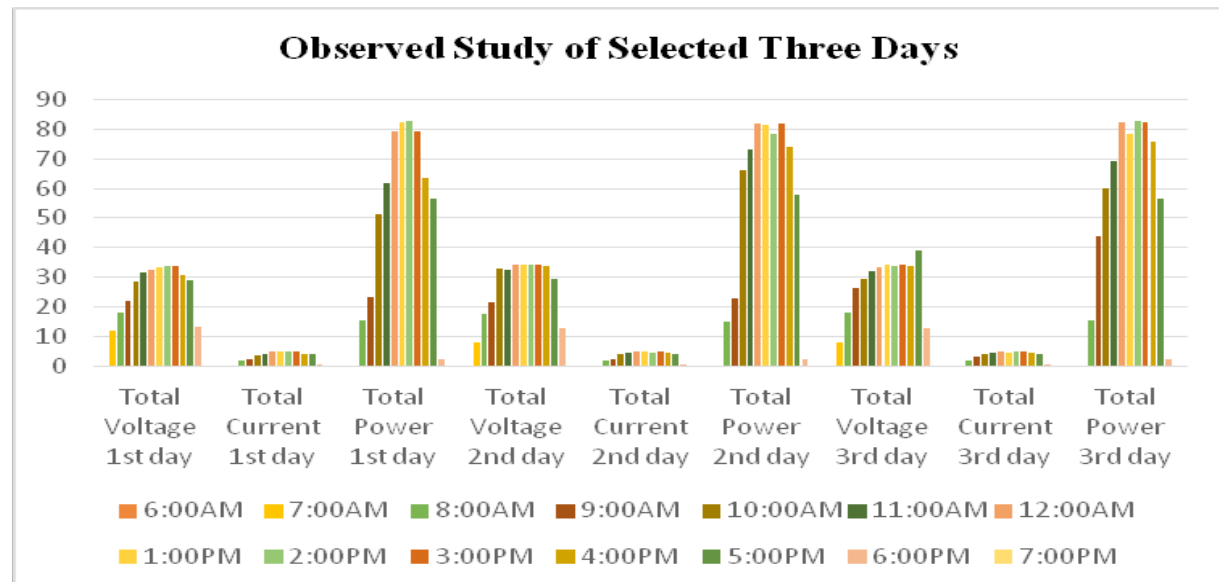

Figure 16. Total voltage, total current and total power measurement of front and rear solar PV (Panel $X$ and $Y$ ) for 1st, 2nd and 3rd-day experiment.

\section{DISCUSSION}

Bifacial solar tracking system performed well while taking results. The power capabilities of the proposed design system had been experimentally tested with two 40W solar panels at different rotations of the time frame under standard test conditions. Hence total 80W solar panel was connected with the different loads and checked one by one in series and in parallel. The tracker was connected in parallel to the voltmeter $(0-100 \mathrm{~V})$. The $12 \mathrm{~V}$ battery keep in closed circuit voltage at a constant level throughout the experiment. The current and voltages have been measured at various time frames throughout the day as the sun moved. To keep the system simple for experimental purpose, the designed system can be rotated manually with the help of proper gearing and motor, but we can actually rotate the panel with external power supply or from the power generated by itself. The required voltage level to maintain the system is $10 \mathrm{~V}$ and the standard alignment of the tracker was kept at $45^{\circ}$. Then the tracker was moved with the help of dc gear motors in the direction of incident solar radiation. So the designed system can extract the maximum amount of solar power from the available radiation 
throughout the day as the sun kept moving from east to west. To analyze the performance of the tracker, the measurements take place at different selected days after every hour from 6:00 AM to 7:00 PM. The voltage level was very good while taking the reading in series connection. On the other hand, the while connected in parallel the maximum current was 4.39 amperes and the total power was 82.61 watts that were too good for our experiment and had a good result. Only very minor discrimination was found between the readings of direct facing panels and reflected or back side connected panel. The rear penal of design solar system is supported by the concentrator for amplifying the strength of reflected irradiation. We took the readings of 3 days and got the results which were very successful in our study of this project design to provide the optimal require value.

\section{ANALYSIS}

The advance bi-facial system is designated for the tracking strategy which enables high collectible energy surplus at medium tracking accuracy which is new and low-cost tracking system with the soft ridge concentrator together. The bi-facial PV panels can double photovoltaic energy harvest in comparison with fixed panels and substantially reduce the price of PV energy which is fundamental aspects of the energy production. The system is designed by combining the two equal watts solar penal having anti-parallel alignment with each other. The rear penal of the design system is supported by concentrator for strengthening the efficiency of the scattered irradiation. The scattered irradiation generates a lot of extra energy due to the design structure of the proposed system. The rear penal of the system primarily increases the efficiency of the module. The voltage of the system is conjoint increases slightly as the timely increasing irradiation strength. The design system illustrates the little bit different in the observed values of front and rear penal of the voltage, current, and power as shown in the Figures 9,12 and 15. The most typically, the designed module's configuration is economical and viable reliable for the local as well as commercial usage. 
The measurement of voltage, current, and power for front and rear solar penal is fitted for the efficiency difference checking of the designed solar system as shown in Figures 7, 10, and 13. We have surveyed the proposed system in the dates as 08 to 10 of the Feb 2019 with the polynomial regression of 6 degrees. The quality of the best fit with the irradiation data is determined by the value of $\mathrm{R} 2$ being close to 1 in the case of front and rear penal. The below table explores the design system in the way of efficiency enhancement. The front and rear penal show the little bit different in the value of $\mathrm{R} 2$ as shown in the Table 1. Hence from the whole observation it is proved that rear penal gives the relatively little bit less value of voltage, current, and power as compared to the front penal. So by adding the values both sides the system expresses the feasible efficiency which is comparatively best then the foreign-based expensive available bi-facial model.

\begin{tabular}{|c|c|c|}
\hline Design Module & Front Penal $\mathbf{R}^{\mathbf{2}}$ & Rear Penal $\mathbf{R}^{\mathbf{2}}$ \\
\hline Voltage & 0.993 & 0.9754 \\
\hline Current & 0.9595 & 0.9509 \\
\hline Power & 0.9677 & 0.9676 \\
\hline
\end{tabular}

Table 1. The 6th degree polynomial $R 2$ values.

The output power for a proposed setup is efficient and reliable. This system provides wide-range usage in developing countries. Our goal is to develop an economical and relatively best combination of hardware and software to enable the manufacturers globally to make and improve the design strategy.

\section{CONCLUSION}

The designed bifacial solar system is more efficient than all other old methods of getting solar power from the sun. The proposed bifacial system is useful for all the off-grid and on-grid areas. The design system is a low-cost solar system that is compatible and reliable. The users are affordable in order to use this system domestically as well as commercially to get great efficiency. The design system is highly efficient and economical reliable in terms of the electrical energy output as compared to the other system. 


\section{ACKNOWLEDGEMENTS}

The efforts of the Department of Electronic Engineering, NED University of Engineering \&Technology and Indus University, Karachi, are acknowledged for its support. 


\section{REFERENCES}

Brady, B., Wang, P. H., Steenhoff, V. \& Brolo, A. G. (2019). Nanostructuring Solar Cells Using Metallic Nanoparticles. Metal Nanostructures for Photonics Nanophotonics, pp. 197-221.

Duan, J., Zhao Y., He, B. \& Tang, Q. (2018). Efficiency enhancement of bifacial dye-sensitized solar cells through bi-tandem carbon quantum dots tailored transparent counter electrodes. Electrochimica Acta, 278, pp. 204-209. doi: http://dx.doi.org/10.1016/j.electacta.2018.05.057

Guerrero-Lemus, R., Vega, R., Kim, T., Kimm, A. \& Shephard, L. E. (2016). Bifacial solar photovoltaics-A technology review. Renewable and sustainable energy reviews, 60, pp. 1533-1549.

Jia, G., Gawlik, A., Plentz, J., \& Andrä, G. (2017). Bifacial multicrystalline silicon thin film solar cells. Solar Energy Materials and Solar Cells, 167, pp. 102108. doi: http://dx.doi.org/10.1016/j.solmat.2017.04.004

Khalil, F, A., Asif, M., Anwar, S., Haq, S. \& Illahi, F. (2017). Solar Tracking Techniques and Implementation in Photovoltaic Power Plants: a Review. Proceedings of the Pakistan Academy of Sciences. Physical and Computational Sciences, 54(3), pp. 231-241.

Khan, M. R., Hanna, A., Sun, X. \& Alam, M, A. (2017). Vertical bifacial solar farms: Physics, design, and global optimization. Applied Energy, 206, pp. 240-248. doi: http://dx.doi.org/10.1016/j.apenergy.2017.08.042

Kim, J S., Kim, D H. \& Hwang, D K. (2018). Efficiency enhancement of bifacial $\mathrm{Cu} 2 \mathrm{ZnSnSe} 4$ thin-film solar cells on indium tin oxide glass substrates by suppressing In-Sn diffusion with Mo interlayer. Fournal of Power Sources, 400, pp. 9-15. doi: http://dx.doi.org/10.1016/j.jpowsour.2018.08.001 
Lamers, M., Özkalay, E., Gali, R. S. R., Janssen, G. J. M., Weeber, A. W., Romijn, I. G., et al. (2018). Temperature effects of bifacial modules: Hotter or cooler? Solar Energy Materials and Solar Cells, 185, pp. 192-197. doi: http://dx.doi.org/10.1016/j.solmat.2018.05.033

Liu, T., Zhao, Y., Duana, J., He, B., Zheng, J., \& Tang, Q. (2018). Transparent ternary alloy counter electrodes for high-efficiency bifacial dyesensitized solar cells. Solar Energy, 170, pp. 762-768.

Livingston, D., Sivaram, V., Freeman, M. \& Fiege, M. (2018). Applying Blockchain Technology to Electric Power Systems. The Council on Foreign Relations, CFR.org. Retrieved from https://www.cfr.org/report/applyingblockchain-technology-electric-power-systems

Lo, G. K., Lim, Y. S. \& Rahman, F. A. (2015). New integrated simulation tool for the optimum design of bifacial solar panel with reflectors on a specific site. Renewable Energy, 81(C), pp. 293-307.

Luque, E G., Torres, F A. \& Escobar, R. (2018). Effect of soiling in bifacial PV modules and cleaning schedule optimization. Energy Conversion and Management, 174, pp. 615-625. doi: http://dx.doi.org/10.1016/j. enconman.2018.08.065

Ooshaksaraei, P., Sopian, K., Zulkifli, R., Alghoul, M. A. \& Zaidi, S H. (2013). Characterization of a Bifacial Photovoltaic Panel Integrated with External Diffuse and Semimirror Type Reflectors. Hindawi Publishing Corporation International Fournal of Photoenergy, Article ID 465837, 7 pages. doi: http://dx.doi.org/10.1155/2013/465837

Pan, A. G., Cardoso, L. S. G. \& Reis, F. S. (2016). Modeling Mathematical of the Behavior of Up Converter when Implemented in Bifacial Silicon Solar Cells. Energy Procedia, 102, pp. 80 - 86. doi: http://dx.doi.org/10.1016/j. egypro.2016.11.321 
Patil, T. G. \& Asokan, S. (2016). A Proficient Solar Panel Efficiency Measurement System: Using Current Measurements. International Conference on Communication and Electronics Systems. doi: http://dx.doi.org/10.1109/ CESYS.2016.7889927

Rajshree, Jaiswal, A. K., Ghaudhary, G. \& Jayswal, V K. (2016) Development of a Dual Axis Solar Tracking System Using LDR Sensor for Roof- Top Applications. Recent Trends in Sensor Research E Technology, 3(3).

Renewables 2017 Global Status Report. (2017). Paris: REN21 Secretariat.

Rodriguez, J., Wang, E. G., Chen, N., Ho, J. W., Li, M., Buatis, J. K., et al. (2018). Towards 22\% efficient screen-printed bifacial n-type silicon solar cells. Solar Energy Materials and Solar Cells, 187, pp. 91-96.

Sengupta, M. (2016). Measurement \& Modeling of Solar Radiation. NREL. Retrieved from https://www.seriius.org/pdfs/india-workshop-measurementmodeling-sengupta-pd.pdf

Sun, X., Khan, M. R., Deline, G. \& Alam, M. A. (2018). Optimization and performance of bifacial solar modules: A global perspective. Applied Energy, 212, pp. 1601-1610. doi: http://dx.doi.org/10.1016/j. apenergy.2017.12.041

Wang, J. M. \& Lu, G. L. (2013). Design and Implementation of a Sun Tracker with a Dual-Axis Single Motor for an Optical Sensor-Based Photovoltaic System. Sensors, 13(3), pp. 3157-3168. doi: http://dx.doi.org/10.3390/ s130303157

White paper. Calculating the additional energy yield of bifiacial solar modules. Retrieved from ///C:/Users/Sabir\%20Ali/Downloads/Calculating-AdditionalEnergy-Yield-Through-Bifacial-Solar-Technology-SW9002US.pdf 
Zhu, W., Wang, M., Wang, Z., Sun, W., He, B. \& Tang, Q. (2017). Photoelectric engineering of all-weather bifacial solar cells in the dark. Electrochimica Acta, 254, pp. 299-307. doi: http://dx.doi.org/10.1016/j. electacta.2017.09.141 


\section{AUTHORS}

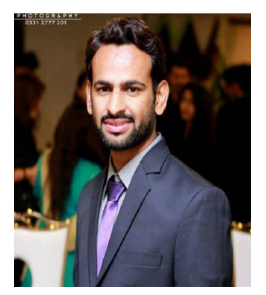

\section{Sabir Ali Kalhoro}

M.Engg (Industrial Electronics) Student from Department of Electronics Engineering NED University of Engineering and Technology Karachi Pakistan.

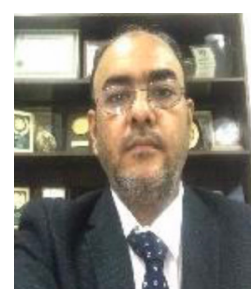

\section{Prof. Dr. Engr. Sayed Hyder Abbas Musvi}

Senior Member of IEEE

Dean at Faculty of Engineering, Science \& Technology Indus University, Karachi, Pakistan.

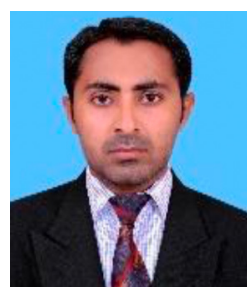

\section{Sikandar Ali}

MS (RS \& GIS) From Department of Geography University of Karachi Pakistan, Currently working as lecturer at Faculty of Engineering, Science \& Technology Indus University Pakistan.

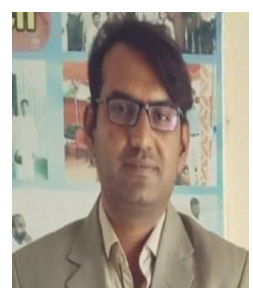

\section{Saadullah Rahoojo}

Lecturer at Department of Geography, University of Sindh Jamshoro, Pakistan.

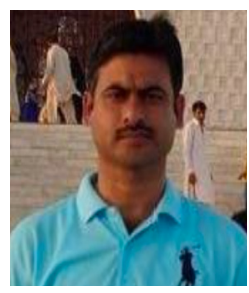

\section{Asim Nawaz}

MS (RS \& GIS) Student Department of Geography University of Karachi. 
Edición Especial Special Issue Mayo 2019

DOI: http://dx.doi.org/10.17993/3ctecno.2019.specialissue2.68-99 